\title{
Activity Budget and Drey Building of Free-Ranging Grizzled Giant Squirrel (Ratufa macroura dandolena)
}

\author{
M. Perera*, S. Wickramasinghe \\ Rajarata University, Sri Lanka \\ *maheshaper89@gmail.com
}

\begin{abstract}
Ratufa macroura dandolena is one of the three distinct sub-species of Giant Squirrels present in Sri Lanka and it is the smallest of the Giant Squirrels in the world. They are being threatened due to habitat loss from deforestation for agricultural, residential and commercial purposes. Activity budgeting is an essential component to form an effective conservation and management system. We conducted six months of study between June and September 2014 and between December 2014 and March 2015 using focal animal sampling techniques to gather behavioral data. Field visits were made three days per week, during the study period and point samples on an individual were recorded at five-minute intervals. Observations on dreys were opportunistically conducted during field visits. The study took place in areas of disturbed regenerating forest within the premises of the Rajarata University in Mihintale. Data collection was done between 07:00 and 17:00 hrs. Grizzled Giant Squirrels were mostly involved in feeding during the period of observation (45.58\%) and was least engaged in other activities $(0.17 \%)$ namely branch shaking and watching the observer. They spent $29.57 \%$ in resting, $14.34 \%$ in locomotion, $3.73 \%$ in intraspecific activities, $1.53 \%$ in grooming, $0.73 \%$ in communicatory behavior and $4.32 \%$ in drey related activities. Feeding mostly occurred from 07:00 to 10:00 hrs and 15:00 to 16:00 hrs according to the diurnal time budget. Majority of the resting was between 11:00 to 15:00 hrs. The walls of the dreys were made by Grewia sp. twigs and the inner floor using leaves of Mangifera indica. Dreys were about $45.95 \pm 0.35$ $\mathrm{cm}$ in length, $30.9 \pm 0.56 \mathrm{~cm}$ in width, $14.85 \pm 0.21 \mathrm{~cm}$ in depth and $412.5 \pm 3.5 \mathrm{~g}$ in weight. We recommend further study of this species at other sites with different forest types to better understand its behavioral ecology and conservation needs. Particular emphasis should be given to studying this species at different altitudes.
\end{abstract}

Keywords: Mammal, Rodent, Behavior, Giant Squirrel, Sri Lanka 